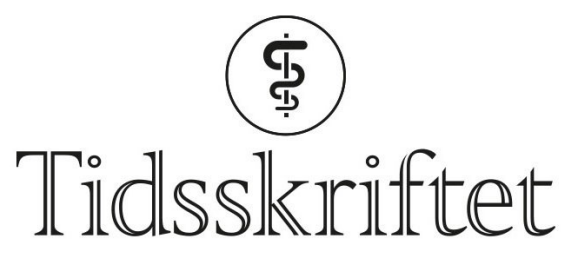

DEN NORSKE LEGEFORENING

\title{
Serotoninet eller samfunnet?
}

ESSAY

TROND F. AARRE

E-post: trond.aarre@helse-forde.no

Trond F. Aarre (f. 1962) er spesialist i psykiatri og rus- og avhengnadsmedisin og avdelingssjef ved Nordfjord psykiatrisenter og fagsjef i Psykisk helsevern, Helse Førde.

Forfattaren har fylt ut ICMJE-skjemaet og oppgjev ingen interessekonfliktar.

Det er ikkje så sikkert at det er nevrovitskapen som vil berge psykiatrien. Faget vil truleg stå seg på samstundes å halde fast på andre perspektiv på korleis menneskelege røynsler fører til plager og funksjonssvikt.

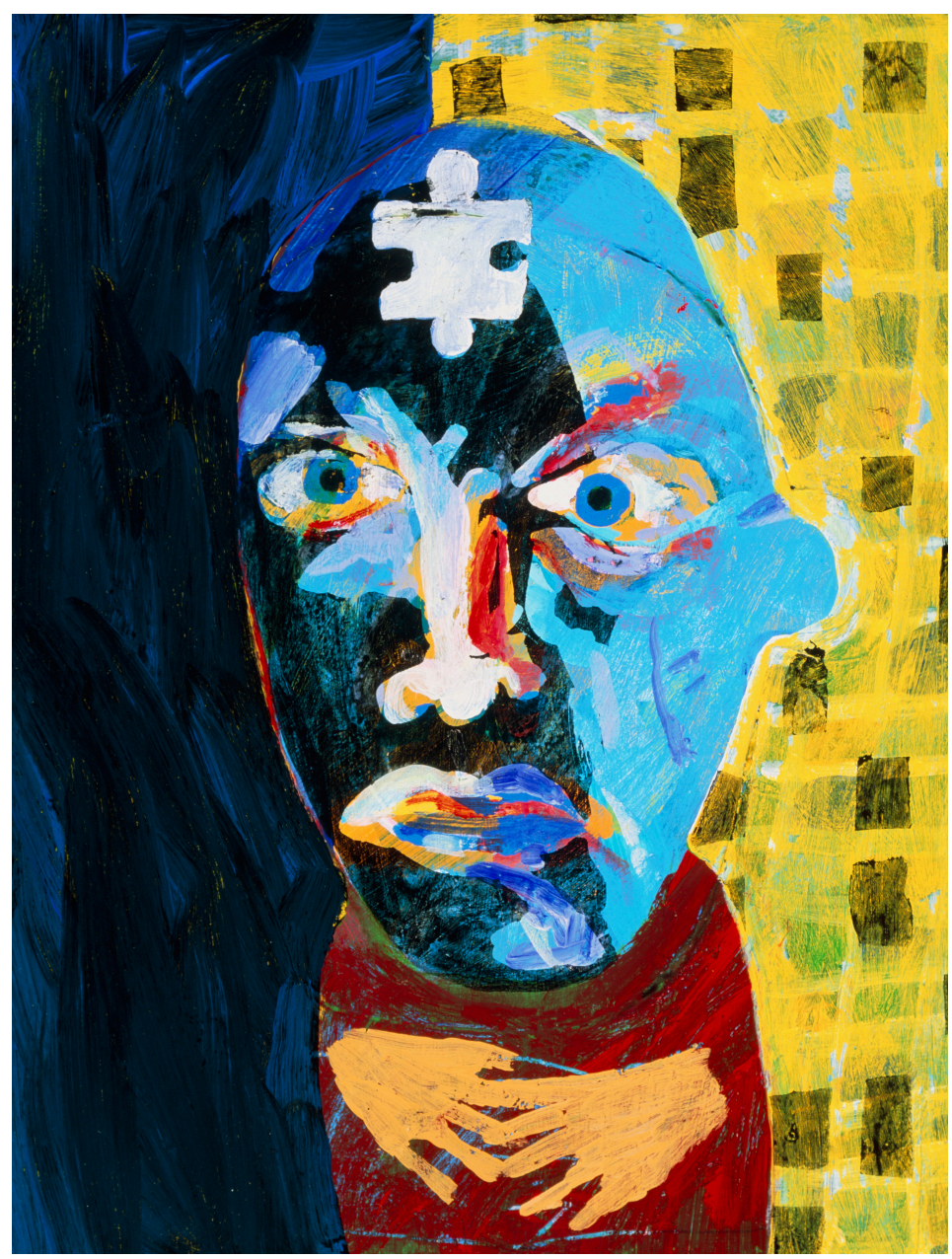

Illustrasjonsfoto: Science Photo Library/NTB scanpix

8. februar. Torsdag morgon, standard opplegg. Frukost, kaffi, siste nytt frå tidsskrifta. I New 
England Journal of Medicine skriv dei at prazosin ikkje hjelper mot posttraumatisk

stressliding (1). Trudde dei verkeleg at ein $\alpha_{1}$-antagonist skulle hjelpe veteranar med å kome til rette med opplevingar på slagmarka? I JAMA Psychiatry Online First rapporterer dei at ruslidingar, faktisk alle psykiske lidingar, er hjernelidingar («brain disorders») (2). Eg sjekkar heimesida til Det kvite huset. Dei har teke bort saka om The BRAIN Initiative, eit tolvårig forskingsprogram som skal revolusjonere forståinga vår av hjernen. Eg finn det att på arkivsidene fra presidentperioden til Barack Obama (3). Der står det, kvitt på blått, at både depresjon og posttraumatisk stressliding er hjernelidingar. Då er det vel sant?

Medan tidsskrift, forskarar og kommentatorar hevdar at psykiske plager best blir forståtte som uttrykk for forstyrra hjernefunksjon (4), og at ein best korrigerer desse forstyrringane medikamentelt, aukar protestane frå lekfolk og organisasjonar. Pasientforeiningar (5), personar som har kome seg av alvorlege psykiske plager (6) og jamvel talspersonar for FN (7) ber om at me ser på psykiske lidingar i andre perspektiv enn det medisinske.

Dei biologiske teoriane er mislikte, men harmen rettar seg kanskje endå meir mot opplevinga av at psykiske plager vert avkontekstualiserte. Folk fortel at plagene deira vert oppfatta som uttrykk for patologi og ikkje vert vurderte i ljos av dei opplevingane som forårsaka dei (8). Kritikarane av det herskande biomedisinske paradigmet kombinerer ofte nidkjær kritikk av den tradisjonelle forskinga med godtruande aksept av alternative studiar (9). Kritikken kan vere befriande og nyttig, men etterlet ein lite overtydd. I dette essayet drøftar eg den ferskaste boka av dette slaget.

\section{Tapte samband}

Ei av dei kritiske røystene er den engelske journalisten Johann Hari, som nyleg ga ut boka Lost connections (10). Undertittelen er ubeskjeden: Uncovering the real causes of depression - and the unexpected solutions. Boka er dels ein gjennomgang av det vitskaplege grunnlaget for ulike syn på depresjon, dels ei sjølvhjelpsbok. På omslaget vert den varmt tilrådd av Emma Thompson, Brian Eno og Elton John. Dette er ikkje primært eit akademisk verk.

Hari var ute av seg på grunn av kjærleikssorg då han var 18 år. Legen brukte under ti minutt på å forklåre at Hari hadde depresjon, ein hjernesjukdom som skuldast serotoninmangel. Legen spurde ikkje kvifor Hari var så lei seg eller kva som hadde skjedd i livet hans, men skreiv ut resept på Seroxat, som Hari brukte i 14 år. Han slutta fordi terapeuten hans peika på at han var like depressiv uansett.

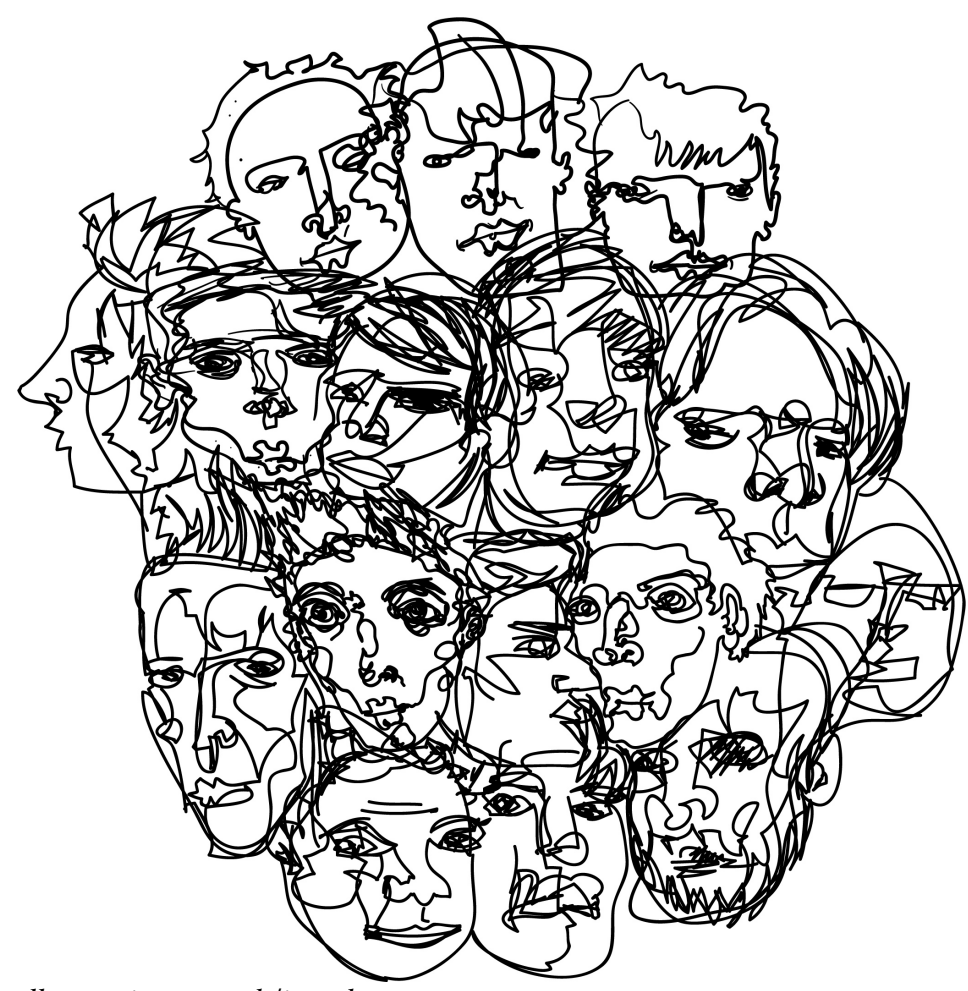

Illustrasjon:Jayesh/iStock 
Hari stilte seg to spørsmål: Kvifor er eg deprimert sjølv når eg tek eit antidepressiv? Og kvifor er det så mange no for tida som kjenner seg deprimerte? Ligg det noko anna enn dårleg hjernekjemi under? Hari undersøkte saka dels ved å lese og dels ved å snakke med forskarar frå samfunnsvitskapane, psykologien og psykiatrien. Det let seg ikkje gjere å ha fullt oversyn over forskinga på dette feltet, men Hari skal ha heider for forsøket. Boka er driven av indignasjonen hans over å vere ført bak ljoset ved å tru på ei forklåring som ikkje held vatn.

\section{Serotoninmangel?}

For Hari sitt argument er det avgjerande at serotoninmangelhypotesen er uhaldbar, men den vert avvist meir enn den vert drøfta. Hari kjenner ikkje den biologiske depresjonsforskinga så godt, og dei han oppsøkjer, kan heller ikkje hjelpe han stort i så måte. Boka hadde stått seg på at Hari fann meir truverdige talspersonar for det biologiske paradigmet.

Konklusjonen hans er at antidepressiv oftast er utilstrekkeleg behandling for depresjon. Det trengst andre tiltak - og andre forklåringar på plagene. Hari trur ikkje at hjerneforskinga blir eit gjennombrot: «Du kan ikkje sjå føre deg handlinga i Breaking Bad ved å skru frå kvarandre fjernsynsapparatet. Sameleis kan du ikkje finne rota til smerta di ved å skru frå kvarandre hjernen din» (s. 145).

Hari trur at årsakene til depresjon i hovudsak er sosiale. Bodskapen vert godt oppsummert $\mathrm{i}$ sitatet frå filosofen og forfattaren Jiddu Krishnamurti (1895-1986): «Det er ikkje eit mål på god helse å vere vel tilpassa eit sjukt samfunn.»

Dersom depresjon er ein mangelsjukdom, trur ikkje Hari at det er serotonin som manglar. Det skortar meir på oppleving av meining, tilhøyrsle og fellesskap. Folk lir under saknet av meiningsfullt arbeid og ei trygg framtid, og økonomiske og sosiale skilnader mellom folk fører til psykisk uhelse. Maktesløyse og meiningsløyse gjer ein ulukkeleg.

Banda mellom folk er færre og svakare enn før. Botemiddelet er å byggje fellesskap som er gjensidige og meiningsfulle for alle partar. Slik folk lever av junk food i staden for mat, hevdar han at dei lever for skrotverdiar i staden for ekte saker. Kvar vi snur oss, høyrer vi den monotone bodskapen om at konsum, status og individualisme er det som gjer oss lukkelege. Individualismen, og liv lausrivne frå naturen og frå fungerande kollektiv, gjer oss sårbare for depresjon. Han oppfattar sitt eige ynskje om ei privat løysing på depresjonen som eit symptom på sjølve den sinnsinnstillinga som forårsaka det heile.

\section{Botemiddel}

Medan Hari til tider maler med for grov pensel og trekk for bastante slutningar i kritikken av antidepressiv og andre individuelle behandlingar, er han nyansert og atterhalden med omsyn til kva konsekvensar ei sosial forståing av depresjon vil få for behandlinga. Han tilrår sosialt orienterte intervensjonar som knyter pasienten tettare til nettverk som skaper meining og fellesskap, stør opp under viktige verdiar og aukar kontakten med naturen og andre menneske.

Individuell jobbstøtte er eit tiltak i tråd med denne tenkinga. Arbeid viser seg å ha mange og omfattande effektar på funksjon og livskvalitet, framfor alt med omsyn til depressive plager (11).

«Befriending» er ein metode utvikla i Storbritannia for å gje emosjonell støtte, ofte i regi av friviljug sektor. Metaanalysar tyder på moderate effektar på depresjon (12). Det er òg studiar som tyder på effekt av tiltak som problemløysing og biblioterapi (13).

\section{Unntaket for sorg}

I den amerikanske diagnosemanualen, DSM-III, definerte ein ikkje sorg som ei psykisk liding, sjølv når det er eit fullt utvikla depressivt syndrom til stades. Unntaket innebar at 
syndromet depresjon av og til skulle reknast som ein normal reaksjon på tapet av ein kjær person. Men også andre påkjenningar kan løyse ut eit depressivt syndrom. Unntaket for sorg er inkonsekvent og viser oss vanskane med å skilje mellom normalitet og psykiske lidingar.

Då unntaket for sorg vart fjerna i DSM-5, som vart publisert i 2013, skapte det intens debatt. Vedtaket vart forsvart av psykiateren Kenneth S. Kendler, i arbeidsgruppa til DSM-5, som skreiv at «Unntaket for sorg må enten bli fjerna, eller utvida slik at ingen depresjon som oppstår under motgang kan diagnostiserast» (mi omsetting) (14). Ved å fjerne unntaket for sorg vart DSM-5 konsekvent. Kostnaden er at sorg vart ei psykisk liding. Synet til Hari er at depresjon oftast er ein normal reaksjon. Men i vår tid, skriv han, har me slutta å spørje kva som gjer oss ulukkelege og prøver heller å blokkere nevrotransmittorane i hjernen som gjer oss i stand til å føle det.

På kontoret, siste nummer av Tidsskriftet ligg i posthylla. Psykiateren Petter Andreas Ringen trur det er eit spørsmål om tid før ny kunnskap frå nevrovitskapane vil bli til hjelp i det kliniske arbeidet (15). Det har dei sagt i hundre år. Ein pasient kjem innom, vil arbeide hjå oss. Han meiner me treng andre perspektiv. «Eg kjenner dette livet. Eg har vore der sjølv, veit meir enn deg om Nav sine stønadsordningar og kvar pasientane skal ringe.» Han har kanskje rett, er det meir erfaringskompetanse - og ikkje nevrovitskap - me treng?

\section{Korleis forstå depresjon?}

Diskusjonen om dei psykiske lidingane har sitt opphav i hjernen eller samfunnet, har ei lang soge. Thomas Szasz peikte i The myth of mental illness på at ein sjukdom eller liding skuldast defektar eller funksjonsforstyrringar (16). Straks det blir påvist forstyrringar eller defektar, er sjukdomane per definisjon ikkje lenger psykiske lidingar, men nevrologiske, metabolske eller genetiske sjukdomar, alt etter som. Påstanden om at psykiske lidingar er ein myte, er difor tautologisk, ifølgje Szasz.

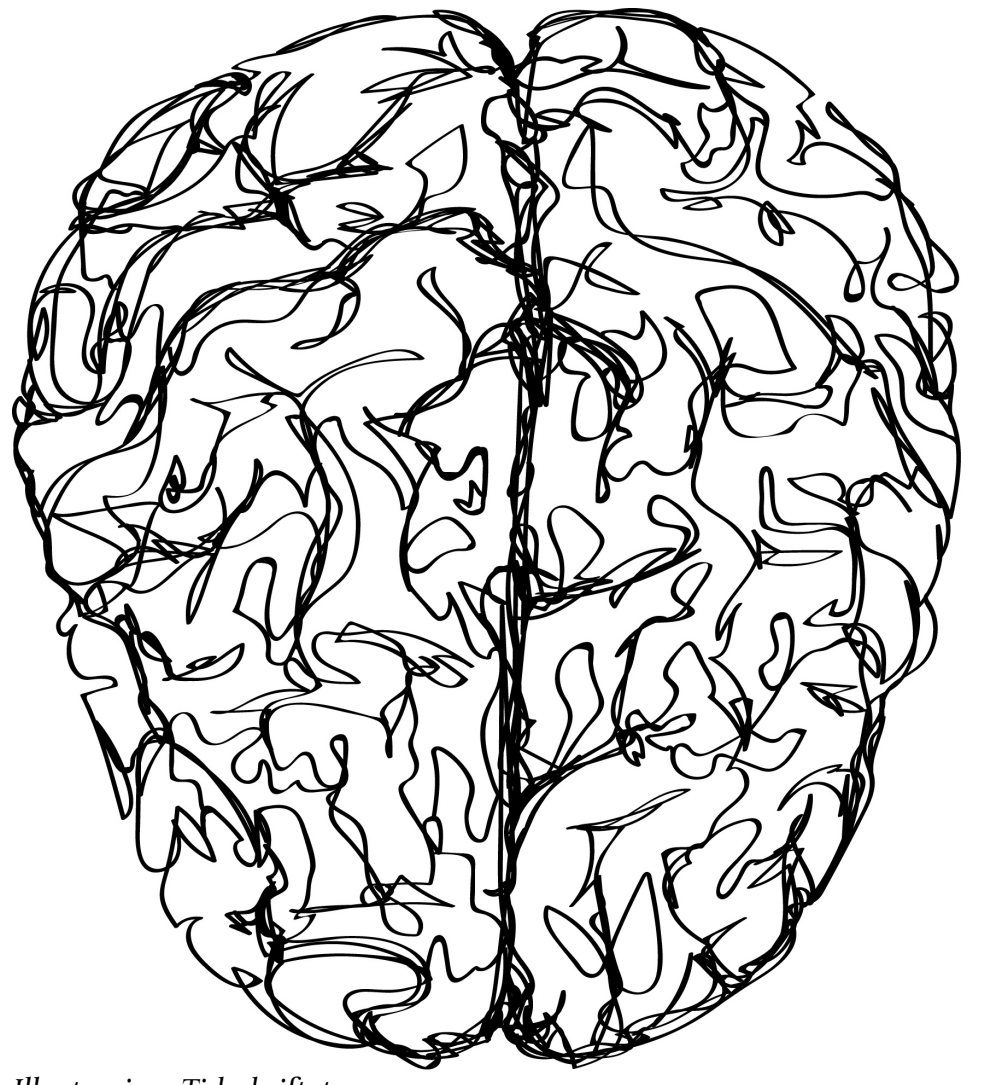

Illustrasjon: Tidsskriftet

Dette er ikkje til hinder for at mange forskarar held fast ved trua på at depresjon er å forstå som hjernelidingar, men samstundes legg vekt på genetiske og miljømessige faktorar. Det vert framleis argumentert for at depresjon skuldast serotoninmangel, men òg 
inflammasjon, nevrodegenerasjon og dysfunksjon i mitokondriane (17).

I dei biologiske, psykologiske og sosiale teoriane studerer ein depresjon på ulike analysenivå. At alt sinnsliv spring ut frå hjernen tyder ikkje at hjerneforsking alltid er det mest fruktbare analysenivået for å forstå tankar og opplevingar. I ei einsidig biologisk tilnærming risikerer ein å blande saman årsak og verknad og individualisere og biologisere samfunnsproblem. Når arbeidsløyse og einsemd aukar førekomsten av depresjon, er det ikkje innlysande at dette bør utforskast nevrobiologisk.

Uansett kor mykje eller lite biologi det er i ein depresjon, må konteksten vere viktig. Depresjon råkar sjeldan i eit vakuum. Til dømes har Dalgard og medarbeidarar vist korleis det er eit dose-respons-tilhøve mellom påkjenningar og førekomst av depresjon (18). Skal ein biologisere psykiske plager, lyt ein unngå ei banalisering som ikkje tek inn over seg det alle veit: at kjenslene våre heng saman med livet vi lever.

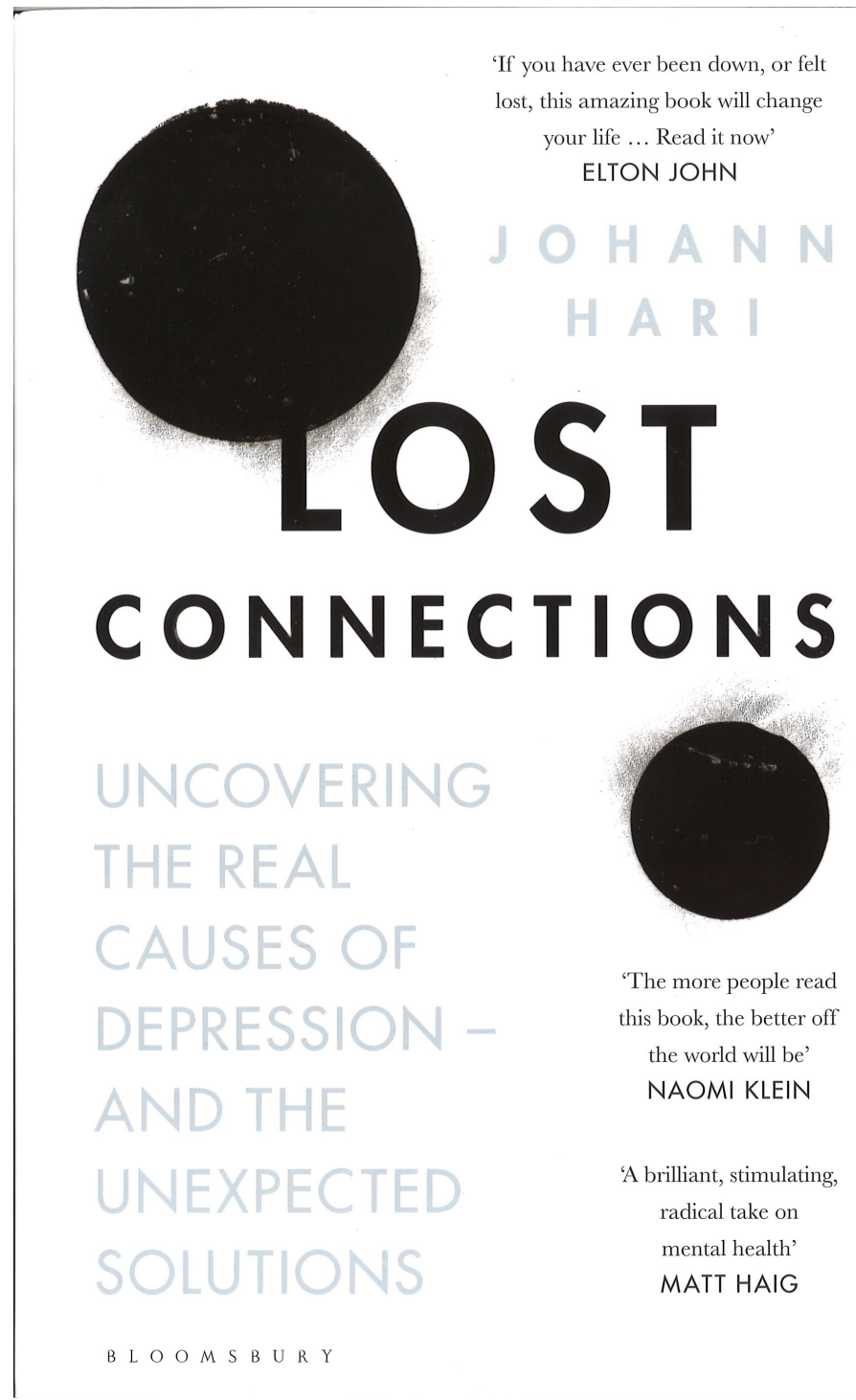

Aktuell bok:Johann Hari. Lost connections.Uncovering the real causes of depression - and the unexpected solutions. London: Bloomsbury, 2018

Klassifikasjonen av psykiske vanskar skjer utan omsyn til kvifor personen har dei aktuelle plagene. Den kliniske handteringa må byrje der klassifikasjonssystema sluttar, altså med den konkrete forståinga av kvifor denne personen har desse plagene. Kritikarane har rett i at korkje diagnostikk eller behandling kan vere kontekstfri.

Mellom 2006 og 2013 auka talet på jenter mellom 14 og 17 år som tok eit antidepressiv med 70 \% her i landet (19). Dette er vanskeleg å sameine med ei reint biologisk forståing av problema. Det må vere noko anna som driv utviklinga.

Ein studie av Einar Kringlen og medarbeidarar viste at førekomsten av depresjon og andre 
psykiske lidingar er mykje lågare i Sogn og Fjordane enn i Oslo (20). Forfattarane meiner at skilnaden i førekomst skuldast sosial stabilitet og tettare band mellom folk i trivselsfylket. Har dei rett i det, må tiltak som aukar samkjensle, fellesskap og tillit mellom folk, redusere førekomsten av depresjon.

Mange oppfattar depressive plager som ein reaksjon på tilhøva dei lever under. Mange oppfattar at dei slit med individuelle problem, og dei vil heller forstå dei konkrete plagene sine enn bli fortalde kva abstrakt kategori dei høyrer til.

I staden for diagnostikk og psykofarmaka vil kritikarane av det biomedisinske paradigmet ha normaliserande tilnærmingar, sosialt orienterte løysingar, inklusjon av dei som kom dårleg ut og sosial aktivisme. Framfor alt ynskjer mange seg ein mindre paternalistisk psykiatri og meir likeverd mellom eksperten og pasienten. Det vil ikkje skade norsk psykiatri å lytte til desse framlegga.

Heim frå kontoret, standard opplegg. Kaffi og Klassekampen, tilbake til tastaturet. Søk på PubMed: «depression-serotonin-hypothesis-review». I oversynsartiklane held ein fast på teorien. Siste nummer av JAMA Psychiatry kjem i innboksen, redaksjonell artikkel frå Oslo om NMDA-reseptorantagonisten esketamin mot behandlingsrefraktær depresjon (21). Forfattarane skriv at sjukdomsmekanismane kan ha med NMDA-reseptoren å gjere. Slik resonnerte dei som lanserte serotoninhypotesen. Går me i sirklar? Eg loggar ut og les endeleg noko på papir - Ivan Illich sin klassikar frå 1974. Av alt eg har lese i dag, er det nok han som har mest rett - det går ein nemesis gjennom medisinen (22), s. 919): «Ved å endre smerte, sjukdom og død frå ei personleg utfordring til eit teknisk problem, eksproprierer medisinsk praksis det potensialet folk har til å handtere menneskelivet autonomt og blir kjelda til ei ny form for uhelse».

\section{LITTERATUR:}

1. Raskind MA, Peskind ER, Chow B et al. Trial of Prazosin for post-traumatic stress disorder in military veterans. N Engl J Med 2018; 378: 507-17. [PubMed][CrossRef]

2. Blanco C, Compton WM, Lopez MF. What is an addictive disorder? JAMA Psychiatry 2018; 75: 229 - 30. [PubMed][CrossRef]

3. The White House President Barack Obama. The Brain Initiative. Brain research through advancing innovative neurotechnologies. https://obamawhitehouse.archives.gov/node/300741

4. Rashidi KH. Psykisk lidelse er fysisk sykdom. NRK ytring 23. desember 2015. https://www.nrk.no/ytring/psykisk-lidelse-er-fysisk-sykdom-1.12699404 (18.3.2018).

5. Landsforeningen We Shall Overcome. Prinsipprogram.

http://wso.no/wp-content/uploads/2017/o1/WSO_prinsipprogram.pdf(18.3.2018).

6. Williams P. Rethinking madness. Towards a pradigm shift in our understanding and treatment of psychosis. San Rafael, CA: Sky's Edge Publishing, 2012.

7. Mendez JE. Report of the special rapporteur on torture and other cruel, inhuman or degrading treatment or punishment. United Nations, 2013.

http://www.ohchr.org/Documents/HRBodies/HRCouncil/RegularSession/Session22/A.HRC.22.53_Engli sh.pdf(18.3.2018).

8. Bisgaard A. Jeg fikk psykiatriske diagnoser som forklaring og piller som behandling. Men jeg var ikke syk. Aftenposten 22.5.2017.

9. Gøtzsche PC, Lund K. Tvangsmedisinering må forbys. Kritisk juss 2016; 42: 118-157. doi:

10.18261/issn.2387-4546-2016-02-03

10. Hari J. Lost Connections. London: Bloomsbury, 2018.

11. Uni Research Helse og Uni Research Rokkansenteret. Effektevaluering av individuell jobbstøtte

(IPS): Sluttrapport. Oslo og Bergen, 2016.

http://uni.no/nb/uni-helse/stress-helse-og-rehabilitering/effektevaluering-av-individuell-jobbsttte-ips- 
$2 /(18.3 \cdot 2018)$

12. Mead N, Lester $\mathrm{H}$, Chew-Graham $\mathrm{C}$ et al. Effects of befriending on depressive symptoms and distress: systematic review and meta-analysis. Br J Psychiatry 2010; 196: 96 - 101. [PubMed][CrossRef]

13. Holvast F, Massoudi B, Oude Voshaar RC et al. Non-pharmacological treatment for depressed older patients in primary care: A systematic review and meta-analysis. PLoS One 2017; 12: e0184666.

[PubMed][CrossRef]

14. Moran M. Bereavement exclusion criteria may be gone from new DSM edition. Psychiatr News 2011; E-publisert 21.10.2011.

15. Ringen PA. Psykiatrien - hvor står du, hvor går du? Tidsskr Nor Legeforen 2018. [PubMed][CrossRef] 16. Szasz T. Fifty years after the myth of mental illness. https://www.rcpsych.ac.uk/pdf/Szaszupdate.pdf (18.3.2018).

17. Fakhoury M. Revisiting the serotonin hypothesis: implications for major depressive disorders. Mol Neurobiol 2016; 53: 2778 - 86. [PubMed][CrossRef]

18. Dalgard OS, Dowrick C, Lehtinen V et al. Negative life events, social support and gender difference in depression: a multinational community survey with data from the ODIN study. Soc Psychiatry Psychiatr Epidemiol 2006; 41: 444 - 51. [PubMed][CrossRef]

19. Hartz I, Skurtveit S, Steffenak AK et al. Psychotropic drug use among o-17 year olds during 2004-2014: a nationwide prescription database study. BMC Psychiatry 2016; 16: 12. [PubMed][CrossRef] 20. Kringlen E, Torgersen S, Cramer V. Mental illness in a rural area: a Norwegian psychiatric epidemiological study. Soc Psychiatry Psychiatr Epidemiol 2006; 41: 713 - 9. [PubMed][CrossRef] 21. Quintana DS, Steen NE, Andreassen OA. The promise of intranasal esketamine as a novel and effective antidepressant. JAMA Psychiatry 2018; 75:123 - 4. [PubMed][CrossRef]

22. Illich I. Medical nemesis. 1974. J Epidemiol Community Health 2003; 57: 919-22.

[PubMed][CrossRef]

Publisert: 26. juni 2018. Tidsskr Nor Legeforen. DOI: 10.4045/tidsskr.18.0209

(C) Tidsskrift for Den norske legeforening 2020. Lastet ned fra tidsskriftet.no 